\title{
(185)
}

\section{Composition of Soil Seed Banks in Relation to Four Different Land Use Patterns in Tropical Moist Forest Lands of Southwest Lowlands, Sri Lanka}

\author{
W.H.M.S.N. Weerasinghe* , B.M.P. Singhakumara \\ Department of Forestry and Environmental Science, University of Sri Jayewardenepura, Sri Lanka \\ *Madshi20@gmail.com
}

\begin{abstract}
The soil seed bank comprises all viable seeds in the soil. Seed banks have been defined as the collections of seeds that can remain dormant in the surface soil until their germination is triggered by an environmental change.

Natural forests in the tropics have been and continue to be subjected to natural and human induced disturbances, which have resulted in their degradation or complete destruction. In places where the sites are left without further interference, the processes of succession that will ultimately lead to re-vegetation of the sites may be initiated. In such cases, soil seed banks serve as one of the major sources of plant re-growth. This study was conducted to document the species composition of soil seed banks in four different landuses and to make a comparison between them. Those are natural forest area in Sinharaja Forest Reserve towards Pitakele, Kekilla fernland, Pine plantations and tea lands in Pitakele village.
\end{abstract}

Three sites from each landuse were randomly selected for the study and ten soil samples were randomly collected from ten different locations in each site and mixed to make a composite. The number of viable seeds in each soil sample was estimated through germination trials.

A total of 1,673 seeds germinated from the soil seed banks of the 12 sites. Most of the tree species were observed in soil seed banks in natural forest and Pine plantations while seeds of herbaceous and graminoid species dominated the soil seed banks of the tea lands and Kekilla fernlands. Natural forest supported the lowest species diversity (Shannon index: H'1.37) in soil seed banks compared to other land uses. Pine lands (Shannon index: H'2.22) and Tea lands (Shannon index: H'1.58) had higher species diversity followed by Kekilla fernland (Shannon index: H'1.47).

Keywords: Soil seed bank, Landuse pattern, Southwest lowlands 